\title{
Patient Presenting with Massive Hematochyluria, Right Thigh Cellulitis and Lymphedema of Leg- A Case Report
}

\author{
Authors \\ Khatua $\mathbf{C} \mathbf{R}^{*}$, Satya $\mathbf{K}^{\#}$, Chandan $\mathbf{G}^{\#}$, Arun $\mathbf{S} \mathbf{V}^{\#}$, Niranjan $\mathbf{N}^{\#}$ \\ *Assistant Professor, ${ }^{\#}$ Post Graduate Student
}

\begin{abstract}
In lymphatic filariasis, patients occasionally present with chyluria, hematochyluria alone or along with other clinical manifestations like lymphangitis, lymphadenitis, elephantiasis, chylocele, chylothorax or chylous ascites. The chyle or hematochyle may clot leading to severe colicky abdominal pain, hypocholesterolemia, hypoproteinemia and anaemia. We report a case of filariasis presenting with massive hematochyluria and lymphangitis.
\end{abstract}

Key Words: Chyluria, hematochyluria, milky urine, lymphangitis.

\section{Introduction}

In filarial endemic areas like India, patients suffering from lymphatic filariasis may occasionally pass urine with a milky or cloudy appearance due to presence of chyle in the urine $^{1,2}$. Chyluria or hematochyluria may result from obstruction or physiologic impairment of renal lymphatics with passage of lymph from the lacteals into the genitourinary tract, which usually occurs in 1-2\% of cases after 10-20 years of initial manifestation, affecting both young male and female equally $^{3,4}$. In most of the time chyluria or hematochyluria is asymptomatic, but sometimes may be polysymptomatic due to the existence of associated conditions such as dysuria, hematuria, renal colic, backache, urinary tract infections (UTI), lymphangitis and serious nutritional consequences like loss of weight and subcutaneous fat, hypoproteinaemia, lymphopenia and anemia ${ }^{5}$. Here we present a case of massive haematochyluria, lymphangitis and lymphedema.

\section{Case Report}

A 42 year male patient got admitted to our hospital with complains of fever and chills for 11 days, painful swelling of right thigh for 6 days and reddish coloured urine for 4 days. Surgery consultation was done for the cellulitis of right thigh and received parenteral antibiotics (cefoperazone+sulbactam) and analgesics. With this treatment, fever subsided but the urine became more reddish, increased in volume to more than 3 litres / day and it was associated with abdominal colicky pain. Routine urine test revealed a case of hematochyluria. Gradually the volume of urine increased to more than 4 liters/day, it became more reddish and the intensity of abdominal colic increased. The routine examination of urine showed excretion of albumin (4+), plenty of RBCs, pus cell (1-2/HPF), urine chyle, urine triglycerides (203) and absent of microfilaria, complete blood count showing $\mathrm{Hb}$ $10.8 \mathrm{gm} \%$, TLC $-16,400 / \mathrm{cmm}$ (with neutrophil 
82\%), QBC MP/microfilaria (-ve) repeatedly, normal serum electrolytes $(\mathrm{Na}+=136, \mathrm{~K}+=3.7)$ blood urea $(36 \mathrm{mg} / \mathrm{dl})$, serum creatinine $(1.1 \mathrm{mg} / \mathrm{dl})$, fasting blood sugar $(102 \mathrm{mg} / \mathrm{dl})$ and negative serum viral markers (HIV, HBsAg and Anti HCV). After 7days inspite of two blood transfusions the $\mathrm{Hb}$ level reduced to $6.4 \mathrm{gm} \%$ from its initial level of $10.8 \mathrm{gm} \%$. This was also associated with reduced level of serum albumin $(1.8 \mathrm{gm} / \mathrm{dl})$, total serum cholesterol $(120 \mathrm{mg} / \mathrm{dl})$, HDL $(25 \mathrm{mg} / \mathrm{dl})$ and LDL $(63 \mathrm{mg} / \mathrm{dl})$. Ultrasound of abdomen and pelvis found features of cystitis. The patient was given Tab Albendazole +
Ivermectin single dose, Tab Diethylcarbamazine (150mg twice daily), parenteral antibiotics continued as before. He received total four units of whole blood transfusion during hospital stay. Gradually the patient improved. The volume and colour of urine gradually became normal (2-2.5 litre/day) with complete disappearance of chyle, triglycerides, blood and albumin from urine within 20 days of treatment and was discharged on the 24th day. During his hospital stay the skin of right thigh and leg developed scaling. He is on regular follow up since last one year. $\mathrm{He}$ is free from symptoms and urine examination is normal.
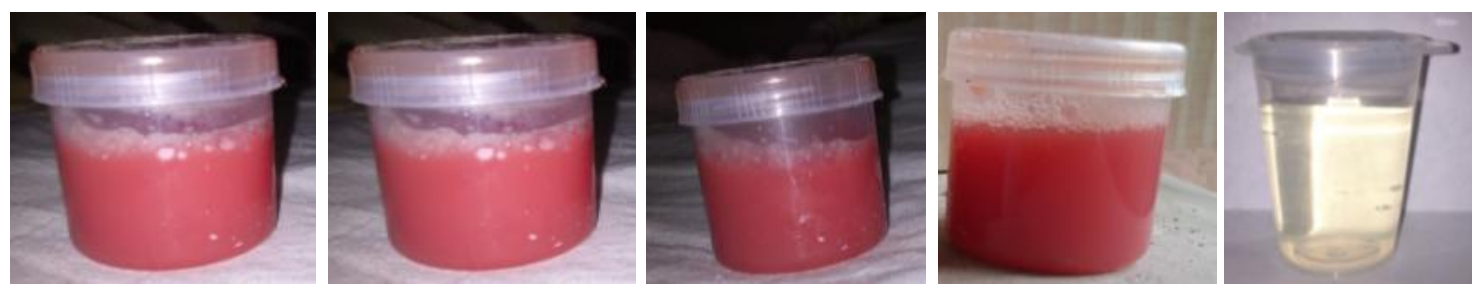

Change of urine colour from admission (day 5) to recovery (day 20)

(A)

(B)

(C)

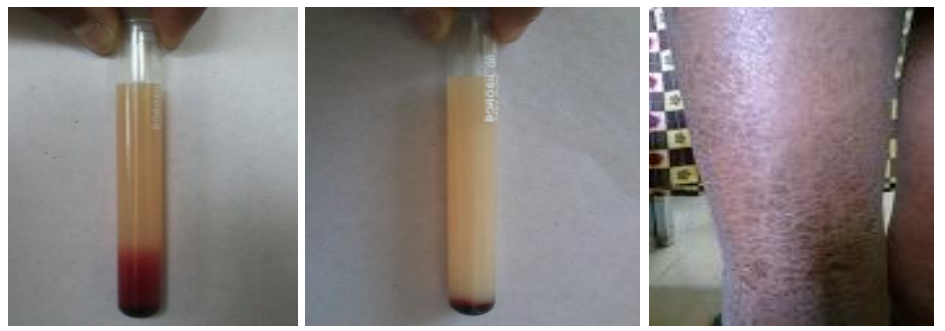

(Changes in urine on prolonged stagnation)

A: Triple layers (upper whitish, middle reddish pink, bottom reddish black on day 2.

B: Upper whitish \& bottom reddish black on day 3.

C: Postdermatitis scaling of the skin which occurred following treatment with Diethylcarbamazine.

\section{Discussion}

Lymphatic drainage of the kidney occurs in a trilaminar fashion ${ }^{6}$. The first lamina lies within the renal parenchyma, the second lies at a subcapsular level and the third lies within the perinephric fat. The lymphatics in the second and third lamina freely intercommunicate. The intrarenal lymphatics emerge as 4-7 trunks, which emerge at the renal hilum to join the 2 nd and $3 \mathrm{rd}$ level lymphatics. These then eventually converge along the renal vessels to the lateral aortic nodes. But in filarial infestation and secondary streptococcal infection of the retroperitoneal lymph nodes, blockage of the lymphatics result in secondary lymphatic hypertension and retrograde flow of chyle from the intestine to the kidneys ${ }^{4}$. And on rupture of lymphatic varices into renal tubules chyluria develops. Chyluria and hematochyluria is usually classified as parasitic or nonparasitic on the basis of its etiopathogenesis ${ }^{7,8}$. The most common etiological factor for chyluria is filariasis and most important is chyluria should be considered filarial unless proven otherwise particularly in the filarial belt ${ }^{9}$. While parasitic forms are almost exclusively responsible for cases detected in Eastern countries, the other 
nonparasitic forms are more frequent in Western countries. Among the parasitic causes of chyluria, Wuchereria bancrofti counts for $90 \%$ of infections. And other parasitic agents like Echinococcus, Cysticercus cellulose, Ascaris lumbricoides, Tinea nana, Cercorrenas hominis and malaria are responsible in rest cases ${ }^{7,8}$. The nonparasitic causes can be congenital lymphatic malformation, injury to kidney with lymphourinary fistulas and obstruction of the lymphatics caused by trauma, abscess, neoplasms, diabetes, pernicious anemia, pregnancy and tuberculosis. The diagnosis of filariasis can be done from the detection of microfilaria in blood and chyle, detection of filarial antigen or antibody $^{10}$ or typical clinical features i.e. lymphedema. In the present case with typical clinical presentation of lymphatic filariasis like lymphangitis, lymphedema of leg with hematochyluria responded to anti-filarial drugs and other symptomatic treatment.

\section{Conclusion}

Chyluria and hematochyluria can be initial clinical features of filarial infestation and in some cases it takes relentless course. Massive hematochyloria may be the only manifestation and these patients can be treated conservatively with anti-filarial drugs and general supports.

\section{References}

1. Nutman TB,Kazura J W: Filariasis. Tropical infectious diseases principles, pathogens and Practice, Vol-2.2006; 98:1152-1159.

2. Paul E Simonsen: Filariasis . Manson's Tropical diseases.2009;84:1477-1490.

3. Lymphatic disorders. Bailey and Love's Short Practice of Surgery .2008 (25th edition); 55:958.

4. Bhat S, Kishore T A,Sulaiman E. Cure of chyluria by intravesical instillation of povidone iodine in a patient with vesicoueretic reflux Indian J Surg 2005 ; 67 : 260-1.

5. Kuzniar J, Uzar J. Kopec W. Herbec R, Modrakowska A. Certain aspects of clinically mild, non-tropical chyluria. Pol Tyg Lek 1991; 46(4-5): 81-3.

6. Taylor MG, Hoerauf A, Bockarie M: Lymphatic filariasis and onchocerciasis. Lancet 2010;376:1175-1185.

7. Diamond E, Schapira HE. Chyluria - A review of the literature. Urology 1985; 26(5): 427-31.

8. Onyeije CI, Sherer DM.Trambert J. Nonfilarial chyluria during pregnancy. Obstet Gynecol 1997; 90: 699-700

9. Singh I, Dargan P, Sharma N. Chyluria - a clinical and diagnostic stepladder algorithm with review of literature. Indian J Urol 2004 ; 20:79-85.

10. Weil GJ,Ramzy RM:Diagnostic tools for filariasis elimination programs. Trends Parasitol 2007;23:78-82. 